\title{
1 million community health workers in sub-Saharan Africa by 2015
}

Prabhjot Singh, Jeffrey D Sachs

During the past 10 years, community health workers (CHWs) have emerged as a focal point of international discussions of primary health-care systems. Although lay community-based health workers have been active for at least 60 years, the Millennium Development Goals (MDGs) in 2000 prompted new discussion of how these workers can help to extend primary health care from facilities to communities. CHWs have since been part of an international attempt to revise primary health-care delivery in low-income settings, and CHW programmes have been changed accordingly. Instead of being regarded as unpaid, lightly trained members of the community who focus mainly on health education and provide basic treatments, CHWs are increasingly envisioned as a trained and paid corps who give advice and treatments, and implement preventive measures. Many national governments, including those of Brazil, Pakistan, Ethiopia, and India, ${ }^{1}$ are making CHWs a cornerstone of the scaling up of community health delivery.

A key difference between the old and new CHW models is that workers are now viewed as an integral and formal part of the health system, with reporting lines, training, supervision, and feedback. Several developments have stimulated efforts to develop a more substantial role for CHWs in primary health care; new mobile health technologies, household-administered rapid diagnostic tests, and expert support systems based on information and communications technologies (ICTs) are greatly enlarging the range of services that CHWs can effectively provide. New ICTs are also enabling improved training and supervision methods, and make the effectiveness of evidence-based community-based protocols delivered by CHWs easier to measure and show. ${ }^{2-4}$

On the basis of the new and expanded idea of CHWs as a subsystem within the formal health-care system, the Earth Institute at Columbia University convened a Technical Taskforce in June, 2011, to examine the best practices for scaling up and integrating CHWs into health systems. The Taskforce agreed that to achieve the MDGs, roughly 1 million CHWs should be trained and deployed in sub-Saharan Africa by 2015. The Taskforce's findings also showed the fairly small cost of scaling up a modern CHW subsystem, estimating that the CHW subsystem costs roughly US $\$ 6.56$ per head per year for the covered (rural) population. Finally, the report underscored the importance of integrating $\mathrm{CHW}$ subsystems into the next generation of primary health-care delivery. ${ }^{5}$ The UN's Broadband Commission, UNAIDS, Roll Back Malaria, and the MDG advocates are among the groups calling for a massive scaling up of CHWs in sub-Saharan Africa.
Before 2000, and in many places until today, CHWs in sub-Saharan Africa were mainly regarded as volunteers who provide a few simple services, mostly in community awareness and disease prevention. However, evidence supports an expanded role of CHWs in communitybased case management, and several reviews and guidelines from WHO now recommend the expansion of CHW activities. ${ }^{2.67}$ In December, 2011, WHO released a 3-year study ${ }^{6}$ highlighting the importance of CHWs at the household level. The report builds on other synthesis studies finding that when deployed at scale, CHW activities can have a profound effect on achievement of MDGs 4, 5, and 6. ${ }^{8-11}$ The new integral role for CHWs uses advances in diagnostic and treatment technologies in the management of malaria, pneumonia, malnutrition, and diarrhoea, ${ }^{2}$ which constitute the most preventable common causes of death of children younger than 5 years in sub-Saharan Africa.

The CHW subsystem should be regarded as an integral part of WHO's six health system building blocks: service delivery, health workforce, information, medicines, financing, and governance. As identified by the CHW Technical Taskforce, the critical inputs for a CHW subsystem include: service delivery clarity and capability; health workforce management; information systems and data use; medical products, point-of-care diagnostics, and technology; financing for CHWs; and leadership and governance of system quality. ${ }^{5}$ Each of these elements corresponds to one of WHO's building blocks.

In the CHW system deployed in the Millennium Villages outlined in the Technical Taskforce Report, there is a minimum ratio of one CHW for 150 households (about 650 people). CHWs systematically circulate throughout their catchment zone, prioritising visits to pregnant women, children younger than 5 years, and sick community members. In the Millenium Villages, CHWs provide health education, pre-approved clinical services, and coordinated referral to health facilities. The CHWs are supported by ICT systems built around mobile telephony, and, increasingly, around smartphones.

CHWs are managed in groups of six by senior CHWs, who are experienced CHWs trained in supportive supervision, and who in turn report to $\mathrm{CHW}$ managers based at the primary care health centre and trained in management techniques. Since a typical Millennium Village site (cluster) has between 30000 and 80000 residents, a site's CHW manager regularly interacts with eight to 20 senior CHWs. This management system is best regarded as an integrated training and supervisory system in which new CHWs can be closely supported as they gain experience in providing
Published Online March 29, 2013 http://dx.doi.org/10.1016 S0140-6736(12)62002-9 School of International and Public Affairs (P Singh MD) and Earth Institute (P Singh, Prof J D Sachs), Columbia University, New York, NY, USA Correspondence to: Dr Prabhjot Singh, Columbia University, Earth Institute, Interchurch Center, New York, NY 10015, USA psingh@ei.columbia.edu http://1millionhealthworkers. org/ 
services to the community. A high-performing CHW subsystem depends on deep integration with the primary health-care system, and investments in supervisory personnel should extend into health facilities.

Finally, note that the scale-up of CHW programmes should not be restricted to low-income and middleincome countries. The USA has a well known shortage of primary care physicians that is expected to worsen as the population ages and the burden of chronic diseases continues to increase. ${ }^{12}$ Over the past two decades, evidence supporting the potential benefits of CHWs in the USA setting has grown, on the basis of a multitude of pilot programmes, particularly for mental health and chronic diseases (ie, depression, ${ }^{13}$ diabetes, ${ }^{14-17}$ hypertension, ${ }^{18}$ asthma, ${ }^{19,20}$ and cardiovascular disease). ${ }^{18,21}$ Expanded CHW programmes are likely to be included in the present round of health-care reform.

With recognition that $\mathrm{CHW}$ subsystem financing must be tailored to a local context, the Technical Taskforce provided evidence of costs for sub-Saharan Africa. Working from a ratio of one CHW to 650 people, the costing exercise made the assumptions that each CHW was provided with a mobile phone and a backpack containing medications and diagnostics, as well as appropriate salary and management. On the basis of this model, the average annual cost of deploying CHWs to the entire rural sub-Saharan African population by 2015, including system initiation and maintenance, would be around US $\$ 2.3$ billion per year, or roughly $\$ 6.56$ per head per year for the rural population covered by the CHW subsystem. ${ }^{5}$ The figure comes to $\$ 3584$ per year to train, equip, and maintain each of the campaign's proposed 1 million CHWs. ${ }^{5}$

To support the achievable goal of 1 million CHWs across sub-Saharan Africa by 2015, additional financing will have to be mobilised to support well tailored, country-specific plans. We regard the Global Fund to Fight AIDS, TB, and Malaria, the Global Alliance for Vaccines and Immunizations (GAVI), and the World Bank as the three most relevant potential partners in such initiatives, making the cancellation of the Global Fund's Round 11 in 2011 particularly threatening to the hundreds of millions of people in sub-Saharan Africa who depend on incremental donor financing to support the scaling up of national health systems. We urge the reinstatement of Global Fund financing to meet the goal of CHW scale-up as early as possible in 2013.

The case for an expanded and dynamic CHW subsystem is very strong. CHW subsystems are proven, effective, low cost, and rapidly scalable components of rural health-care systems. The Millennium Villages Project and several national programmes are showing that rapid deployment is possible and highly effective. For the first time, an expert Technical Taskforce with key stakeholders and experts has reached a consensus for operational and financial guidance for the next generation of CHWs. Further research into the mechanics of
CHW subsystems is needed to ensure that the evidence base stands the test of sustained implementation, while new initiatives to extend the career prospects of CHWs are crucial for sustainability. CHW scale-up in lowincome countries, particularly sub-Saharan Africa, will be a crucial stepping stone towards achievement of the MDGs and the overarching aim of health for all.

\section{Contributors}

Both authors contributed equally.

\section{Conflicts of interest}

We declare that we have no conflicts of interest. JDS is Director of the Millennium Villages Project. PS advises CHW System development and is the Co-Chair of the One Million Community Health Worker campaign.

\section{References}

1 Liu A, Sullivan S, Khan M, Sachs S, Singh P. Community health workers in global health: scale and scalability. Mt Sinai J Med 2011; 78: 419-35.

2 Bhutta ZA, Lassi ZS, Pariyo G, Huicho L. Global experience of community health workers for delivery of health related millennium development goals: a systematic review, country case studies, and recommendations for integration into national health systems. http://www.who.int/workforcealliance/knowledge/ publications/CHW_FullReport_2010.pdf (accessed Jan 20, 2013).

3 Darmstadt GL, Bhutta ZA, Cousens S, Adam T, Walker N, de Bernis L, for the Lancet Neonatal Survival Steering Team. Evidence-based, cost-effective interventions: how many newborn babies can we save? Lancet 2005; 365: 977-88.

4 Lewin S, Munabi-Babiqumira S, Glenton C, et al. Lay health workers in primary and community health care for maternal and child health and the management of infectious diseases (review). Cochrane Database Syst Rev 2010. 3: CD004015

5 Singh P for Technical Task Force. 1 million community health workers: global technical taskforce report.http://1millionhealth workers.org/files/2013/01/1mCHW_TechnicalTaskForceReport.pdf (accessed Jan 20, 2013).

6 The Partnership for Maternal, Newborn \& Child Health. A global review of the key interventions related to Reproductive, Maternal, Newborn and Child Health (RMNCH). Partnership for Maternal, Newborn \& Child Health, 2011. http://www.who.int/pmnch/topics/ part_publications/essentialinterventions14_12_2011low.pdf (accessed Jan 20, 2013)

7 Lehmann U, Sanders D, for WHO. Community health workers: what do we know about them? The state of the evidence on programmes, activities, costs and impact on health outcomes of using community health workers. http://www.who.int/hrh/ documents/community_health_workers.pdf (accessed Jan 30, 2013).

8 Sazawal S, Black RE, for the Pneumonia Case Management Trials Group. Effect of pneumonia case management on mortality in neonates, infants, and preschool children: a meta-analysis of community-based trials. Lancet Infect Dis 2003; 3: 547-56.

9 Kidane G, Morrow RH. Teaching mothers to provide home treatment of malaria in Tigray, Ethiopia: a randomised trial. Lancet 2000; 356: 550-55.

10 Koenig S, Léandre F, Farmer P. Scaling-up HIV treatment programmes in resource-limited settings: the rural Haiti experience. AIDS 2004; 18 (suppl 3): S21-25.

11 Gyapong M, Garshing B. Lessons learned in home management of malaria: implementation research in four African countries. World Health Organization Special Programme for Research \& Training in Tropical Diseases, 2007. http://whqlibdoc.who.int/ publications/2007/9789241595186_eng.pdf (accessed Jan 20, 2013).

12 Bureau of Health Professions, Health Resources and Services Administration, US Department of Health and Human Services. The physician workforce: projections and research into current issues affecting supply and demand. Washington: Health Resources and Services Administration, 2008. http://bhpr.hrsa.gov/ healthworkforce/reports/physwfissues.pdf (accessed Jan 20, 2013).

13 Roman LA, Gardiner JC, Lindsay JK, et al. Alleviating perinatal depressive symptoms and stress: a nurse-community health worker randomized trial. Arch Womens Ment Health 2009; 12: 379-91. 
14 Spencer MS, Rosland AM, Kieffer EC, et al. Effectiveness of a community health worker intervention among African American and Latino adults with type 2 diabetes: a randomized controlled trial. Am J Public Health 2011; 101: 2253-60.

15 Otero-Sabogal R, Arretz D, Siebold S, et al. Physician-community health worker partnering to support diabetes self-management in primary care. Qual Prim Care 2010; 18: 363-72.

16 Babamoto KS, Sey KA, Camilleri AJ, Karlan VJ, Catalasan J, Morisky DE. Improving diabetes care and health measures among hispanics using community health workers: results from a randomized controlled trial. Health Educ Behav 2009; 36: 113-26.

17 Cherrington A, Ayala GX, Amick H, Allison J, Corbie-Smith G, Scarinci I. Implementing the community health worker model within diabetes management: challenges and lessons learned from programs across the United States. Diabetes Educ 2008; 34: 824-33.
18 Brownstein JN, Chowdhury FM, Norris SL, et al. Effectiveness of Community Health Workers in the care of people with hypertension. Am J Prev Med 2007; 32: 435-47.

19 Clark NM, Lachance L, Doctor LJ, et al. Policy and system change and community coalitions: outcomes from allies against asthma. Am J Public Health May 2010; 100: 904-12.

20 Postma J, Karr C, Kieckhefer G. Community health workers and environmental interventions for children with asthma: a systematic review. J Asthma 2009; 46: 564-76.

21 Balcazar H, Alvarado M, Hollen ML, et al. Salud Para Su

Corazon-NCLR: a comprehensive Promotora outreach program to promote heart-healthy behaviors among hispanics. Health Promot Pract 2006; 7: 68-77. 